

\section{Os caminhos fragmentados da proteção humana: o peticionamento individual, o conceito de vítima e o amicus curiae como indicadores do acesso aos sistemas interamericano e europeu de proteção dos direitos humanos*}

\section{The fragmented ways of human} protection: the subject right of petition, the concept of victim and the amicus curiae as indicators of access to the Inter-American and European Human Rights Protection Systems

\section{Resumo}

O relatório de pesquisa no âmbito do direito constitucional-internacional, cujo objeto é o acesso universal aos sistemas de proteção de direitos humanos, questiona qual o papel do sujeito perante estes sistemas, no contexto de uma idéia de fragmentação do Direito. Em pesquisa epistemológica e aplicada, com investigação documental e bibliográfica, (re)discute-se a noção de sujeito que, em virtude da fragmentação da pós-modernidade, se apresenta em sua dupla dimensão: como vítima de violação de direitos humanos e como fomentador da construção de uma esfera pública em matéria de direitos humanos. Como delimitação ao tema, realiza-se a comparação jurídica entre os sistemas regionais - europeu e interamericano - de proteção dos direitos humanos, em três perspectivas: análise institucional, exame do acesso ao sistema e verificação da construção jurisprudencial dos conceitos em matéria de direitos humanos com a participação do sujeito. A pesquisa é realizada no âmbito do grupo de pesquisa Internacionalização do Direito. A discussão das hipóteses de pesquisa está estabelecida em dois pontos. O primeiro diz respeito ao avanço dos sistemas regionais - europeu e interamericano - de proteção dos direitos humanos na construção jurisprudencial e na efetivação dos valores fundamentais protegidos pelas respectivas Convenções, que permitem o acesso direto do indivíduo aos respectivos órgãos de controle. $\mathrm{O}$ segundo se refere à atuação do sujeito como vítima, na condução de valores comuns, e a criação de condições de possibilidade do acesso dos indivíduos e demais atores nos sistemas de proteção dos direitos humanos podem ser o início da construção de uma esfera pública comunicativa mundial, em matéria de direitos humanos. O sistema europeu e o sistema interamericano, que se encontram em diferentes momentos e possuem diferentes velocidades, desenvolveram um pano de fundo comum, acerca da necessidade de se respeitar a dignidade da pessoa humana. Todavia, no momento atual, em que se examina o processo de fertilização cruzada à luz da Internacionalização dos Direitos, percebe-se um sistema interamericano preocupado em evoluir em sua saga na busca da concretização dos direitos humanos e em um modelo de

Artigo recebido em 11/12/2012

Artigo aprovado em 25/01/2013

Doutorando e Mestre em Direito das Relações Internacionais pelo Centro Universitário de sília (UniCEUB), Pesquisador do grupo (UniCEUB/Collegè de France), Professor da Graduação em Direito e em Relações Internacionais e da Pós-Graduação Lato Sensu do UniCEUB. Líder dos grupos de pesquisa Debatendo com o STF e Efetividade do Sistema Interamericano de Proteção dos Direitos Humanos. Email: andre.gontijo@gmail.com 
racionalidade que permita o acesso direto do indivíduo perante a Corte, sem a destruição do patrimônio simbólico construído pela Comissão Interamericana; enquanto o sistema europeu, a seu turno, se vê em um momento de atenção, principalmente no choque entre as demandas da economia (o "combate" aos imigrantes ilegais) e a alma construída em torno dos direitos humanos (a proteção da pessoa humana, independentemente de sua origem ou de seu patrimônio jurídico).

Palavras-chave: Direito constitucional-internacional. Acesso do sujeito aos sistemas de proteção dos direitos humanos. Papel do sujeito na construção jurisprudencial dos sistemas europeu e interamericano de proteção dos direitos humanos.

\section{Abstract}

The research report has elaborated in constitutional-international law context, and the object is the universal access to the human rights protection systems. The research question is what is the subject role in these protection systems. That is an epistemology and applied research, with documentary and bibliographical technical research, that (re)discusses the notion of subject in the post-modernity fragmentation context, that is presented in double dimension: as victims of human violations and to encourage the construction of the public sphere of human rights. As the demarcation issue, the comparison is about the need to respect the dignity of the human person. However, at present, which analyzes the process of cross-fertilization in the light of Internationalization of Law, we can see an Inter-American system concerned with evolving saga in his quest for the realization of human rights and a model of rationality that allows direct access to the person before the court, without the destruction of the symbolic heritage built by Inter-American Comission of human rights, while the European system, in turn, finds herself in a moment of attention, especially in the clash between the demands of the economy (the "combat" to illegal immigrants) and soul built around human rights (protection of the human person, regardless of their origin or of their legal heritage).

Key-words: Constitutional-International Law. The subject access to European and Inter-American human rights system. The subject role in judicial construction of European and Inter-American human rights system.

\section{Introdução}

Atualmente, os Estados enfrentam um contexto internacional antes não existente, em que atores públicos, experts e atores privados possuem vez e voz no processo de tomada de decisão. Discute-se um processo amplo de mudança, o qual desloca as estruturas destes processos centrais de tomada de decisão das atuais sociedades e abala os quadros de referência, responsáveis por conferir aos sujeitos uma ancoragem estável no mundo social. Vive-se uma "crise de identidade" em que as antigas noções de identidade do sujeito - que estabilizaram o mundo social - estão em declínio, em virtude da assunção de novas identidades, fragmentadoras do sujeito moderno, considerado unificado. ${ }^{2}$

A crise de identidade surge a partir do processo de deslocamento ou "descentração" do sujeito, que consiste no deslocamento dos indivíduos tanto de seu lugar no mundo social e cultural, quanto dele próprio. Trata-se de uma mudança estrutural que está transformando as sociedades no final do século XX e início do século XXI, com a fragmentação das paisagens culturais - de classe, gênero, sexualidade, etnia, raça e nacionalidade - que

\footnotetext{
2 HALL, Stuart. A identidade cultural na pós-modernidade. 11. ed. Rio de Janeiro: DP\&A, 2006. p. 7.
} 
mantinha sólida as localizações do sujeito no plano da identidade social e no plano da identidade pessoal, como sujeito integrado. ${ }^{3}$

O sistema jurídico, como um todo, convive com pelo menos três concepções diferentes de identidade no seu cotidiano: (a) a identidade do sujeito do Iluminismo; (b) a identidade do sujeito sociológico; e (c) a identidade do sujeito pós-moderno.

O sujeito do Iluminismo centra-se na perspectiva individualista do eu, na identidade de uma pessoa, de um indivíduo totalmente centrado e unificado, dotado das capacidades de razão, de consciência e de ação. ${ }^{4}$

Por outro lado, a noção de sujeito sociológico reflete a complexidade na qual o mundo moderno a reflete, e a consciência de que o centro não é apenas a autoconsciência do sujeito, mas sim a relação com outras pessoas, em que se verifica a troca de experiência e valores, sentidos e símbolos - em resumo, a formação da cultura. ${ }^{5}$

A partir dessa concepção, a identidade é formada pela interação do eu com a sociedade. Constitui o núcleo essencial do sujeito o "eu real", mas este dialoga continuamente com as esferas culturais "exteriores" e com as outras identidades por elas oferecidas. Desse modo, há o preenchimento do espaço pessoal com a esfera pública, com o alinhamento dos sentimentos subjetivos com os lugares objetivos, a partir da projeção dos valores individuais nessas identidades culturais e, simultaneamente, a internalização dos significados e valores do mundo externo. Assim, o sujeito é "costurado" à estrutura a partir da identidade. ${ }^{6}$

Anteriormente, com uma identidade unificada e estável, o sujeito passava por grandes transformações: passando agora a ser considerado um sujeito fragmentado, composto de várias identidades; em função das mudanças estruturais e institucionais, as identidades estão entrando em colapso, sendo que o próprio processo de identificação do sujeito constitutivo tornou-se mais pro-

${ }^{3}$ HALL, Stuart. A identidade cultural na pós-modernidade. 11. ed. Rio de Janeiro: DP\&A, 2006. p. 9.

${ }^{4}$ HALL, Stuart. A identidade cultural na pós-modernidade. 11. ed. Rio de Janeiro: DP\&A, 2006. p. 10.

${ }^{5}$ HALL, Stuart. A identidade cultural na pós-modernidade. 11. ed. Rio de Janeiro:DP\&A, 2006. p. 11.

${ }^{6}$ HALL, Stuart. A identidade cultural na pós-modernidade. 11. ed. Rio de Janeiro:DP\&A, 2006. p. 11. visório, variável e problemático. ${ }^{7}$

Passa-se a ter um reconhecimento de uma identidade do sujeito no âmbito dos sistemas regionais de proteção dos direitos humanos. Em função da fragmentação, além do papel de vítima, o sujeito passa a ter o papel de fomentador do sistema, com o acesso universal, contribuindo para o processo de tomada de decisão em matéria da luta contra a violação dos direitos humanos.

Isso porque, sob certas circunstâncias, seus diferentes elementos e identidades podem ser conjuntamente articulados, cuja estrutura da identidade, entretanto, sempre permanece aberta. Embora seja uma articulação parcial, cuida-se de uma "[...] recomposição da estrutura em torno de pontos nodais particulares de articulação"s que, na verdade, constitui a formulação de um sujeito adaptado à realidade dos sistemas de proteção dos direitos humanos.

Todavia, cada sistema regional parte de pelo menos um ponto comum - a proteção de direitos humanos -, mas desenvolve identidades culturais diversificadas, a partir da relação de pertencimento às culturas étnicas, raciais, linguísticas, religiosas e de cada Estado-Parte. ${ }^{9}$

O processo de reconhecimento dos direitos da pessoa humana não tende à difusão de um modelo único, a partir de um ponto único. Concentra-se, sobretudo, na emergência de diversos pontos (ou regiões) do mundo, nascendo de uma vontade compartilhada de reconhecer direitos comuns a todos os seres humanos. Nesse aspecto, a universalidade dos direitos fundamentais à pessoa humana implica a troca de culturas e valores e não o desejo de se construir um sentido único e universal. Logo, cada sociedade vivencia, de algum modo, os aspectos dos direitos humanos, à sua maneira, mas permite a aproximação das "diferentes culturas", em uma perspectiva evolutiva, a fim de que se enriqueçam com a troca mútua de experiências e procedimentos. ${ }^{10}$

${ }^{7}$ HALL, Stuart. A identidade cultural na pós-modernidade. 11. ed. Rio de Janeiro: DP\&A, 2006. p. 12.

${ }^{8}$ HALL, Stuart. A identidade cultural na pós-modernidade. 11. ed. Rio de Janeiro: DP\&A, 2006. p. 18.

9 Cf. HALL, Stuart. A identidade cultural na pós-modernidade. 11. ed. Rio de Janeiro: DP\&A, 2007. p. 8.

${ }^{10}$ LIMA, José Antonio Farah Lopes de. Convenção européia de direitos humanos. Leme: J. H. Mizuno, 2007. p. 19. 
Nesse contexto, as lógicas próximas, porém, distintas e diferenciadas dos sistemas regionais de proteção dos direitos humanos podem dialogar entre si, a fim de se alcançar o aperfeiçoamento da interpretação dos conteúdos essenciais que visam resguardar a dignidade do ser humano. Essas lógicas apresentam-se fragmentadas, em diferentes processos de interação, mas se revelam conexas por meio de diferentes instrumentos, como a compreensão dos julgados e a sua fertilização cruzada, e o acesso dos diferentes tipos de sujeito aos processos de tomada de decisão nestes sistemas regionais de proteção dos direitos humanos.

O indivíduo não é considerado sujeito de direito internacional, mas consegue ter acesso ao processo de tomada de decisão em matéria de direitos humanos por meio da Internacionalização dos Direitos, a qual expressa a convivência nunca antes tão próxima e tão complexa entre o nacional e o internacional.

Para se adequarem ao fenômeno que lhes apresentam, fórmulas são buscadas pelos Estados. Alguns se retiram em um ambiente fechado, outros apresentam uma falsa abertura ao externo, enquanto há aqueles que se preocupam em conjugar uma ordem constitucional saudável com uma esfera internacional em formação. O presente ensaio visa apresentar, a título comparativo, a perspectiva institucional do acesso do indivíduo aos sistemas regionais europeu e interamericano de proteção dos direitos instrumento a metodologia dos processos de internacionalização do direito, permite mapear os procedimentos e valores jurídicos considerados comuns no âmbito dos sistemas (regionais) de proteção dos direitos humanos, a fim de se criar uma esfera pública, com status de regime normativo próprio em matéria de direitos humanos.

Para comprovar essa hipótese, foram selecionadas, como forma de delimitação temática, três formas de o indivíduo se apresentar perante os sistemas regionais: o peticionamento individual, a definição do conceito de vítima e a intervenção de terceiros. Cada um desses tópicos visa, de acordo com os parâmetros traçados, apresentar precedentes jurisprudenciais (na medida em que eles existem) que constroem os respectivos instrumentos no âmbito dos sistemas regionais, por meio da interpretação e integração dos institutos.

O conceito de vítima dos sistemas regionais de proteção dos direitos humanos pode ser considerado o embrião do mapeamento de valores comuns, realizado pelos estudos jurídicos comparativos para a internacionalização do direito. A fertilização cruzada entre os sistemas regionais de proteção dos direitos pode demonstrar diferenças culturais entre os sistemas, mas, em contrapartida, identificar metodologias e conceitos comuns na proteção e na luta contra a violação dos direitos humanos.

Nessa perspectiva, a criação de condições de possibilidade do acesso dos indivíduos e demais atores nos sistemas de proteção dos direitos humanos pode contribuir para densificar os elementos já existentes na esfera pública comunicativa mundial em matéria de direitos humanos, conferindo a possibilidade de esta esfera pública ser o instrumento de uso comum para a irradiação dos direitos humanos por meio do acesso dos indivíduos e demais atores nos sistemas de proteção dos direitos humanos, desenvolvendo-se, pela fragmentação do direito, um regime comum em matéria de direitos humanos.

\section{0 acesso aos sistemas regionais de proteção dos direitos humanos via peticionamento individual}

\subsection{Sistema europeu}

Perante o reforço do caráter judicial do sistema, a apreciação do direito de petição como método de implementação dos direitos humanos no plano internacional 
deve levar em conta a legitimidade dos peticionários e as condições do uso e da admissibilidade das petições. Os dois instrumentos - tanto do artigo 33 como do artigo 34 da Convenção - são aptos a realizar a verificação de compatibilidade dos sistemas jurídicos nacionais com os ditames do conteúdo normativo previsto pela Convenção Europeia, o chamado controle de convencionalidade. Todavia, inicialmente, apenas os Estados-Partes tinham a autorização para realizar tal verificação em concreto (em um caso específico) e em abstrato, enquanto que o exercício de petição individual permitia o exame da convencionalidade apenas em concreto. É o que entendia a Corte Europeia no caso Golder vs. Reino Unido, ${ }^{11}$ em que o indivíduo não poderia suscitar à Corte Europeia que determinada lei não era compatível com a Convenção, mas apenas poderia fazê-lo se a lei fosse aplicada em prejuízo a um direito fundamental, previsto na Convenção.

A Corte Europeia evoluiu seu posicionamento de modo que o indivíduo pode acessar a Corte se demonstrar que uma lei supostamente contrária aos ditames da Convenção (a partir da avaliação de percepção de risco) possa lhe ser aplicada, o que feriria o seu direito fundamental em abstrato. Desse modo, qualquer indivíduo pode atacar a convencionalidade de qualquer norma geral de seu Estado. Este entendimento restou consignado no caso Norris vs. Irlanda (1988), em que a Corte Europeia asseverou:

A Corte também concorda com o Governo que as condições que regem cada pedido ao abrigo do artigo 25 da Convenção não são necessariamente as mesmas que os critérios nacionais relativos ao locus standi. As regras nacionais a este respeito poderão servir finalidades diferentes das contempladas pelo artigo 25 e, ao mesmo tempo em que às vezes podem ter os mesmos efeitos análogos, eles não precisam ser sempre assim $[\ldots]$.

\footnotetext{
${ }^{11}$ EUROPEAN COURT OF HUMAN RIGHTS. Plenary. Golder vs. The United Kingdom (Application n. ${ }^{\circ} 4451 / 70$ ), j. 21.2.1975. Disponível em: <http://www.echr.coe.int/echr/>. Acesso em: 21 ago. 2008. Ver, em especial, o seguinte trecho do $\$ 39$ : “(...) It is not the function of the Court to elaborate a general theory of the limitations admissible in the case of convicted prisoners, nor even to rule in abstracto on the compatibility of Rules 33 para. 2, 34 para. 8 and 37 para. 2 of the Prison Rules 1964 with the Convention. Seised of a case which has its origin in a petition presented by an individual, the Court is called upon to pronounce itself only on the point whether or not the application of those Rules in the present case violated the Convention to the prejudice of Golder (De Becker judgment of 27 March 1962, Series A no. 4, p. 26)...
}

Seja como for, a Corte decidiu que o artigo 25 da Convenção habilita os indivíduos para sustentarem que uma lei viola os seus direitos por si só, na ausência de uma medida individual de implementação, se eles correm o risco de serem diretamente afetados por ela [...]. ${ }^{12}$

É importante destacar que, embora a Corte Europeia tenha permitido a abstração com o direito de petição, este não pode ser exercido mediante "ação popular", isto é, o requerente não pode se queixar em nome da população em geral. Até mesmo o Estado-Parte, na competência do artigo 33, o faz na função de proteção diplomática do indivíduo ou de grupos específicos. ${ }^{13}$

Assim, sob o manto da Convenção Europeia de Direitos Humanos, a construção de uma jurisprudência reconhecendo a autonomia do direito de petição individual vem sendo desenvolvida, o que transforma o direito ao recurso individual na pedra angular do mecanismo de salvaguarda instaurado pela Convenção. ${ }^{14}$ Além do controle em abstrato de convencionalidade, outra consequência decorrente destes julgados é a interpretação do conceito de vítima, a qual deve ser vista de forma autônoma, independentemente de conceitos de direito interno.

\subsection{Sistema interamericano}

O sistema de peticionamento é definido pelo artigo 44, em que qualquer indivíduo ou grupo de pessoas ou, ainda, organização não governamental legalmente reconhecida em um ou mais Estados-Membros da OEA pode apresentar petições que contenham denúncias ou

${ }^{12}$ EUROPEAN COURT OF HUMAN RIGHTS. Norris vs. Ireland (Application n. ${ }^{\circ}$ 10581/83), j. 26.10.1988. Disponível em: <http://www.echr.coe.int/echr/>. Acesso em: 25 jun. 2008. Tradução livre de: "The Court further agrees with the Government that the conditions governing individual applications under Article 25 (art. 25) of the Convention are not necessarily the same as national criteria relating to locus standi. National rules in this respect may serve purposes different from those contemplated by Article 25 (art. 25) and, whilst those purposes may sometimes be analogous, they need not always be so ] Be that as it may, the Court has held that Article 25 (art. 25) of the Convention entitles individuals to contend that a law violates their rights by itself, in the absence of an individual measure of implementation, if they run the risk of being directly affected by it [...]."

${ }^{13}$ Por todos, ver EUROPEAN COURT OF HUMAN RIGHTS. Third Section. Segi and gestoras pro-amnistia vs. 15 States of European Union (Application(s) n. ${ }^{\circ}(s) 6422 / 02$ e 9916/02), Decision of inadmissible in 23.5.2002. Disponível em: <http:// www.echr.coe.int/echr/>. Acesso em: 25 jun. 2008.

${ }^{14}$ LIMA, José Antonio Farah Lopes de. Convenção européia de direitos humanos. Leme, São Paulo: J. H. Mizuno, 2007. p. 33. 
queixas de violação dos direitos humanos previstos pela Convenção por um dos Estados-Partes.

Diferentemente da Corte Europeia de Direitos Humanos, para ser objeto de "ataque" do sistema de peticionamento, o Estado-Parte deve declarar que reconhece a competência da Comissão Interamericana para receber e examinar as comunicações de violação dos direitos humanos, nos termos do artigo 45. Caso o Estado-Parte não apresente declaração deste tipo, a Comissão Interamericana não poderá admitir nenhuma comunicação contra ele.

O tratamento do direito de petição individual no Sistema Interamericano de Direitos Humanos não dispõe do acesso universal e irrestrito do indivíduo perante a Corte Interamericana de Direitos Humanos, em um primeiro momento. Neste sistema regional, o acesso universal é franqueado apenas à Comissão Interamericana, consoante o disposto no artigo 44 do Pacto San José da Costa Rica. ${ }^{15}$

Com o decorrer da evolução do sistema interamericano, outros mecanismos de proteção dos direitos humanos facultaram o acesso do indivíduo, grupos de indivíduos e entidades não governamentais ao sistema. $\mathrm{O}$ Protocolo Adicional de San Salvador determina a utilização do peticionamento individual perante a Comissão Interamericana (e eventualmente perante a Corte Interamericana) quando o direito à organização sindical (artigo $8^{\circ}$, inciso I, alínea “a”) e o direito à educação (artigo 13) forem violados por uma ação diretamente imputável a um Estado-Parte signatário do Protocolo. ${ }^{16}$

Nessa mesma linha, a terceira parte do artigo $8^{\circ} \mathrm{da}$ Convenção Interamericana para Prevenir e Punir a Tortura estabelece que, se as pessoas são submetidas à tortura, o caso poderá ser submetido às instâncias internacionais, cuja competência tenha sido aceita por esse Estado, uma vez esgotados os procedimentos jurídicos internos.

\footnotetext{
15 "Artigo 44. Qualquer pessoa ou grupo de pessoas, ou entidade não-governamental legalmente reconhecida em um ou mais estados-membros da Organização, pode apresentar à Comissão petições que contenham denúncias ou queixas de violação desta Convenção por um Estado-Parte."

${ }^{16}$ A crítica que permanece, a partir de outra leitura deste dispositivo, é a possibilidade de o sistema Comissão Interamericana/CORTE Interamericana restringir o acesso do peticionamento individual quando da violação de outros direitos, em função de uma leitura restritiva deste enunciado do Protocolo.
}

Com o Regulamento da Comissão Interamericana, ${ }^{17}$ no seu artigo 23 , a possibilidade de o indivíduo, grupo de indivíduos e ONGs acessarem o sistema tornou-se institucionalmente elastecida, visto que as petições podem ser interpostas sobre supostas violações dos direitos humanos reconhecidos em todos os tratados protetivos do sistema interamericano: na Convenção Americana sobre Direitos Humanos, no Protocolo Adicional à Convenção sobre Direitos Humanos em Matéria de Direitos Econômicos, Sociais e Culturais, no Protocolo à Convenção Americana sobre Direitos Humanos Referente à Abolição da Pena de Morte, na Convenção Interamericana para Prevenir e Punir a Tortura e na Convenção Interamericana para Prevenir, Punir e Erradicar a Violência contra a Mulher, em conformidade com as respectivas disposições e com as do Estatuto da Comissão e do presente Regulamento.

Por um lado, esse sistema de peticionamento merece ser revisto com certa urgência, uma vez que os indivíduos não estão legitimados para levar uma demanda perante a Corte Interamericana diretamente. Dessa forma, se um Estado-Parte obteve a vitória em um assunto no âmbito da Comissão Interamericana, não há incentivo (seja pela Comissão Interamericana, seja pelo Estado-Parte) de submeter (ainda que seja outro o julgamento) à Corte Interamericana, a qual representa a

\footnotetext{
${ }^{17}$ Aprovado pela Comissão em seu $109^{\circ}$ período extraordinário de sessões, realizado de 4 a 8 de dezembro de 2000, e modificado em seu $116^{\circ}$ período ordinário de sessões, realizado de 7 a 25 de outubro de 2002 , em seu $118^{\circ}$ período ordinário de sessões, realizado de 6 a 24 de outubro de 2003 e em seu $126^{\circ}$ período ordinário de sessões, celebrado de 16 a 27 de outubro de 2006.
} 
única via para que todos os meios de proteção operem de forma plena. ${ }^{18}$

A violação dos direitos humanos conduz o sujeito à posição central do sistema, na medida em que as atrocidades cometidas despertam a consciência jurídica dos povos para a necessidade de revisar as próprias bases do sistema internacional. Esta mudança corresponde ao reconhecimento da necessidade de que todos os Estados respondam pela maneira como tratam as pessoas que se encontram sob sua jurisdição, a fim de evitar novas ofensas aos direitos humanos. ${ }^{19}$

A sentença de um Tribunal Internacional de Direitos Humanos serve para um amplo propósito, pois não apenas resolve as questões jurídicas suscitadas em um caso concreto, mas também tem o escopo de esclarecer e desenvolver o sentido das normas de direitos humanos e, desse modo, contribuir para a sua obediência pelos Estados-Partes. ${ }^{20}$

Com essa orientação, no caso Castillo Petruzzi y otros vs. Perú, a Corte Interamericana consagrou a natureza jurídica e o alcance do direito de petição individual. Além de resgatar a posição do sujeito como parte cen-

\footnotetext{
${ }^{18}$ PACHECO GÓMEZ, Máximo. La Competencia Consultiva de la Corte Interamericana de Derechos Humanos. In: CORTE INTERAMERICANA DE DERECHOS HUMANOS. El sistema interamericano de protección de los derechos humanos en el umbral de siglo xxi: memoria del seminario. 2. ed. Relator: Antônio Augusto Cançado Trindade. San José: CORTE Interamericana, 2003, p. 79. Este caminho entre a Comissão Interamericana e Corte Interamericana, que se mostra delicado, ante a possibilidade da primeira não submeter a análise da violação dos direitos humanos para a segunda, foi objeto de preocupação na competência consultiva, exarada pela CORTE Interamericana (Cf. CORTE INTERAMERICANA DE DERECHOS HUMANOS. Opinión consultiva OC-5/85, 13.11.1985. La colegiación obligatoria de periodistas arts. 13 y 29 Convención americana sobre derechos humanos. Disponível em: <http://www.corteidh.or.cr/>. Acesso em 23 ago. 2008. Ver, em especial, o $\$ 26)$.

19 TRINDADE, Antônio Augusto Cançado. Tratado de direito internacional dos direitos humanos. Porto Alegre: S. A. Fabris Editor, 2003. v. 3, p. 486.

${ }^{20}$ EUROPEAN COURT OF HUMAN RIGHTS. Plenary. Ireland vs. The United Kingdom (Application n. ${ }^{\circ}$ 5310/71), j. 18.1.1978. Disponível em: <http://www.echr.coe.int $>$. Acesso em: 25 jun. 2008. Ver, em especial, o seguinte trecho: do $\$ 154$ “(...) The Court's judgments in fact serve not only to decide those cases brought before the Court but, more generally, to elucidate, safeguard and develop the rules instituted by the Convention, thereby contributing to the observance by the States of the engagements undertaken by them as Contracting Parties (Article 19)."
}

tral do sistema jurídico, assevera que o direito de petição contribui para assegurar o respeito pelas obrigações de caráter objetivo que vinculam os Estados-Partes, incluindo a influência na mudança do sistema jurídico interno e da prática dos Órgãos públicos do Estado. Afirma, ainda, que a legitimidade do direito de petição estende-se a todo e qualquer peticionário, inclusive pode prescindir da manifestação da própria vítima, o que amplia a eficácia de sua abrangência, isto é, além de qualquer pessoa - nacional, estrangeira, refugiada ou apátrida - poder peticionar, necessariamente não precisa ser vítima, podendo resguardar o direito de terceiros. ${ }^{21}$

Foi o que aconteceu no caso em análise, em que a entidade peticionária - FASIC, entidade não governamental com registro no Chile - não precisou adequar-se aos requisitos legais de um determinado ordenamento jurídico interno, pois supriu o requisito exigido pelo artigo 44 da Convenção Americana: é registrada em um dos países membros da OEA. Além de demonstrar a característica da desnacionalização, ${ }^{22}$ a proteção dos direitos humanos acionada pelo exercício do direito de petição individual se efetua à luz da noção de garantia coletiva,

${ }^{21}$ CORTE INTERAMERICANA DE DERECHOS HUMANOS. Caso Castillo Petruzzi y otros vs. Perú. Sentencia de 4.9.1998 (Excepciones Preliminares). Voto do Juiz Cançado Trindade. Disponível em: <http://www.corteidh.or.cr/>. Acesso em: 28 jun. 2008. Ver, em especial, os $\$ \$ 4-5$ e 26.

${ }^{22}$ Este amplo acesso também restou consignado na Segunda Opinião Consultiva da Corte Interamericana de Direitos Humanos, sobre o efeito das reservas sobre a entrada em vigência da Convenção Americana (de 24.9.1982), em que foi invocada esta particularidade como demonstração da grande importância atribuída pela Convenção Americana às obrigações dos Estados-Partes em relação aos indivíduos, sem a intermediação de outro Estado. Nesse sentido, ver em especial o $\$ 32$ : “Debe destacarse, además, que la Convención al contrario de otros tratados internacionales sobre derechos humanos, inclusive la Convención Europea, confiere a los individuos el derecho de presentar una petición contra cualquier Estado tan pronto como éste haya ratificado la Convención (artículo 44). En contraste, para que un Estado pueda presentar una denuncia contra otro Estado cada uno de ellos debe haber aceptado la competencia de la Comisión para tramitar denuncias entre Estados (artículo 45). Esto indica la gran importancia que la Convención atribuye a las obligaciones de los Estados Partes frente a los individuos, las cuales pueden ser exigidas de una vez, sin la mediación de otro Estado." (Cf. CORTE INTERAMERICANA DE DERECHOS HUMANOS. Opinión Consultiva OC-2/82, 24.9.1982. El efecto de las reservas sobre la entrada en vigencia de la Convención Americana sobre Derechos Humanos. Disponível em: <http://www.corteidh.or.cr/>. Acesso em: 28 jun. 2008). 
demonstrando o amplo alcance conferido ao artigo 44 da Convenção. ${ }^{23}$

Nesse caso específico, restou de forma emblemática a posição de Antônio Augusto Cançado Trindade, à época Juiz da Corte Interamericana, na defesa do direito de peticionamento individual. Para ele, cada uma das ações realizadas pelas instituições no contexto do direito internacional dos direitos humanos tem contribuído, a seu modo, para o gradual fortalecimento da capacidade processual do demandante na esfera internacional. ${ }^{24}$

\section{0 conceito de vítima no contexto do acesso aos sistemas regionais de proteção de direitos humanos}

\subsection{Sistema europeu}

A Corte é a única competente para decidir se o interessado é vítima para os efeitos do artigo 34 da Convenção. ${ }^{25}$ Assim, a noção de vítima deve ser entendida de uma forma autônoma, independentemente da maneira como o ordenamento jurídico interno de cada EstadoParte regule o interesse e a qualidade de agir. Nesse aspecto, ainda que não exista capacidade de agir em nível interno, isso não afeta a possibilidade de a vítima apresentar a própria queixa. ${ }^{26}$

É considerada "vítima" quem for diretamente atingido pelo ato objeto do litígio, sofrendo ou correndo o risco de sofrer os seus efeitos. ${ }^{27}$ A qualidade de vítima não depende sempre da existência de prejuízo ${ }^{28}$ mas está associada à eficácia do recurso interno, ou seja, dependerá da compensação que o recurso interno lhe tiver concedido. $^{29}$

${ }^{26}$ BARRETO, Irineu Cabral. A Convenção europeia dos direitos do homem anotada. 3. ed. Coimbra: Coimbra, 2005. p. 288.

${ }^{27}$ EUROPEAN COURT OF HUMAN RIGHTS. Fourth Section. Ünal Tekeli vs. Turkey (Application n. ${ }^{\circ}$ 29865/96), j. 16.11.2004. Disponível em: <http://www.echr.coe.int/echr/>. Acesso em: 26 jun. 2008. Ver, em especial, o $\$ 35$ : “The Court is not required to determine whether the obligation on the applicant to change her surname as a result of marrying when she was a trainee lawyer may adversely affect her subsequent professional life. It reiterates that besides professional or business contexts, the surname concerns and identifies a person in their private and family life regarding the ability to establish and develop social, cultural or other relationships with other human beings (see, mutatis mutandis, Niemietz v. Germany, judgment of 16 December 1992, Series A no. 251-B, $\$$ 29). The Court considers that in the instant case the refusal to allow the applicant to use just her own surname, Ünal, by which she claimed to have been known in private circles and in her cultural or political activities may have considerably affected her non-professional activities. The applicant is therefore a victim of the impugned decisions (see, to the same effect, Burghartz v. Switzerland, judgment of 22 February 1994, series A no. 280-B, $₫ 18$ )."

${ }^{28}$ EUROPEAN COURT OF HUMAN RIGHTS. Third Section. Jorge Nina Jorge and Others vs. Portugal (Application n. ${ }^{\circ}$ 52662/99), j. 19.2.2004. Disponível em: <http://www.echr.coe. int/echr/>. Acesso em: 27 ago. 2008. Ver, em especial, o $\$ 39$ : "La Cour relève à cet égard que la circonstance, alléguée par le Gouvernement, que le prolongement de la phase judiciaire de la procédure n'aurait pas porté préjudice aux requérants, ceux-ci ayant déjà obtenu le versement des indemnisations en cause, ne saurait ébranler ce constat. En effet, à supposer même qu'il y ait eu absence de préjudice, ce que la Cour trouve loin dêtre établi, il convient de rappeler qu'une violation de la Convention se conçoit même en l'absence de préjudice (Ilhan c. Turquie [GC], n 22277/93, \$52, CEDH 2000-VII)."

${ }^{29}$ EUROPEAN COURT OF HUMAN RIGHTS. Grand Chamber. Apicella vs. Italy (Application n. ${ }^{\circ}$ 64890/01), j. 29.3.2006. Disponível em: <http://www.echr.coe.int/echr/>. Acesso em: 26 jun. 2008. Ver, em especial, o $\$ 71$ : "In so far as the parties appear to link the issue of victim status to the more general question of effectiveness of the remedy and seek guidelines on affording the most effective domestic remedies possible, the Court proposes to address the question in a wider context by giving certain indications as to the characteristics which such a domestic remedy should have, having regard to the fact that, in this type of case, the applicant's ability to claim to be a victim will depend on the redress which the domestic remedy will have given him or her." 
Por outro lado, o requerente deve manter a qualidade de vítima ao longo do processo e não apenas durante a apresentação da queixa. Se o interesse desaparece, tendo em vista o reconhecimento e a reparação do dano, a queixa deve ser arquivada, face ao caráter subsidiário. Todavia, uma decisão favorável ao requerente não é suficiente para lhe retirar a qualidade de vítima. Aliás, mesmo com a alteração da legislação em descompasso com a Convenção, o status de vítima permanece se a situação criada for mantida. ${ }^{30}$

Com efeito, um elemento importante ao qual deve ser dado enfoque é a participação da família e de pessoas próximas à vítima em temas de violação de direitos humanos. A Corte iniciou a preocupação com esse tema em função do tratamento das consequências da morte do requerente durante a pendência do processo perante o sistema regional. Inicialmente, a morte do requerente implicava o arquivamento da queixa, salvo se a causa fosse transmissível; assim, os respectivos herdeiros poderiam substituir o requerente. ${ }^{31}$

No entanto, a Comissão considerava que as queixas apresentadas sob o pálio do artigo $6^{\circ}$ da Convenção - dentre elas, as referentes à equidade e à duração do

\footnotetext{
${ }^{30}$ A minuciosidade do conceito de vítima chega a ser alta, haja vista que, em se tratando de uma duração do processo excessiva, nem a transação entre as partes e nem a decisão final que não considere expressamente, para o cálculo da indenização, essa duração, fazem perder a "qualidade de vítima" (Cf. BARRETO, Irineu Cabral. A convenção europeia dos direitos do homem anotada. 3. ed. Coimbra: Coimbra Editora, 2005. p. 289).

${ }^{31}$ EUROPEAN COURT OF HUMAN RIGHTS. Chamber. $X$. vs. France (Application n. ${ }^{\circ}$ 18020/91), j. 31.3.1992. Disponível em: <http://www.echr.coe.int/echr/>. Acesso em: 30 jun. 2008. Ver, em especial, o $\$ 26$ : “The applicant died on 2 February 1992. In a letter of 6 February his parents expressed their wish to continue the proceedings. In such circumstances the Commission has sometimes struck out of its list cases concerning compliance with the reasonable time requirement laid down in Article 6 para. 1 (art. 6-1) of the Convention. It has taken the view that the complaint was so closely linked to the person of the deceased that the heirs could not claim to have a sufficient interest to justify the continuation of the examination of the application (reports of 9 October 1982 on application no. 8261/78, Kofler v. Italy, Decisions and Reports no. 30, p. 9, paras. 16-17, and of 13 January 1992 on application no. 12973/87, Mathes v. Austria, paras. 18-20). The Court, however, in accordance with its own case-law, accepts in the present case that Mr X's father and mother are now entitled to take his place (see, inter alia, the Vocaturo v. Italy judgment of 24 May 1991, Series A no. 206-C, p. 29, para. 2, the G. v. Italy judgment of 27 February 1992, Series A no. 228-F, p.65, para. 2, and the Pandolfelli and Palumbo v. Italy judgment of 27 February 1992, Series A no. 231-B, p.16, para. 2).”
}

processo - estavam intrinsecamente ligadas à pessoa do requerente, o que as levava ao arquivamento em função da morte. ${ }^{32}$

A Corte Europeia, por outro lado, divergia do entendimento da Comissão, pois adotou sempre uma atitude flexível, concedendo aos herdeiros do falecido a possibilidade de prosseguirem no processo sem a preocupação do direito em causa. Esse entendimento foi aceito pela
32 EUROPEAN COMMISSION OF HUMAN RIGHTS. DECISION of 13.7.1983 on the admissibility of the Application n. ${ }^{\circ}$ 9502/81. S. vs. The United Kingdom. Disponível em: <http:// www.echr.coe.int/echr/>. Acesso em: 30 jun. 2008. Ver, em especial, o seguinte trecho: "7. Nor does the Commission consider that there is any question of general interest affecting the observance of the obligations undertaken by the High Contracting Parties which would justify the continued examination of the application. In this respect it notes that the Commission and Court have previously examined similar issues concerning the conformity of disciplinary proceedings with the requirements of Article 6(1) in many other cases (see e .g . Le Compte, Van Leuveu and De Meyere and Albert and Lecompte, op. cit., and the cases referred to therein). 8. Moreover the present proceedings concern a system of professional disciplinary procedures which, for historical reasons, is peculiar to the Bar of England and Wales. The continued examination of the application could not therefore be justified on the basis that important questions of principle affecting the observance of the Convention by other High Contracting Parties are at stake." 
Comissão ${ }^{33}$ e, após a reformulação do sistema regional, foi mantido pela atual Corte Europeia. ${ }^{34}$

Se a vítima está impossibilitada de agir, outra pessoa pode apresentar a queixa em nome dela. ${ }^{35}$ Além dessa hipótese de representação processual, nos casos em que existe um vínculo particular e pessoal com a vítima (sem, necessariamente, ser um laço familiar), admite-se a apresentação de queixa, em nome próprio, por aqueles que se considerem "vítima indireta". Em outras palavras, pelos que possam alegar que a violação lhes causou um prejuízo ou que têm interesse pessoal válido em que seja posto termo à ofensa, é o caso de pais e irmãos apresentados como vítimas em função do falecimento de seu parente ${ }^{36}$ ou por pessoas que conviveram em comum - como em união estável - por um longo período ${ }^{37}$ e desejam o reconhecimento e a reparação da violação de determinados direitos fundamentais.

A questão de saber se um parente também é vítima depende de parâmetros de aferição traçados pelos casos concretos analisados pela Corte que se baseiam na existência de fatores particulares que conferem a esse parente uma dimensão e um caráter distintos da perturbação afetiva comum a esses casos. Entre esses fatores, figuram a proximidade do parentesco, as circunstâncias particulares da relação, à medida que o parente testemunhou os acontecimentos, a forma como as autoridades públicas reagiram a seus pedidos. Logo, é a atuação do parente diante das autoridades públicas na busca da resolução da questão que constitui a essência da violação e se distancia da emoção natural da perda do falecido. ${ }^{38}$

Há ainda casos em que parentes e entes próximos da vítima falecida buscam proteger a sua memória e o

${ }^{37}$ EUROPEAN COURT OF HUMAN RIGHTS. Fourth Section. Velikova vs. Bulgaria (Application n. ${ }^{\circ} 41488 / 98$ ). Decision of 18.5.1999. Disponível em: <http://www.echr.coe.int/ echr/>. Acesso em: 30 jun. 2008. Ver, em especial, o seguinte trecho: "The Court recalls that a couple who have lived together for many years constitute a "family" for the purposes of Article 8 of the Convention and are entitled to its protection notwithstanding the fact that their relationship exists outside marriage (see the Johnston and Others v. Ireland judgment of 18 December 1986, Series A no. 112, p. 25, \$ 56). In the present case the applicant raises complaints in respect of the death of Mr. T., with whom she had lived for more than 12 years. They had three children together. In these circumstances, the Court has no doubt that the applicant may claim to be personally affected by, and therefore a victim of, the alleged violations of the Convention in respect of the death of Mr. T. and the subsequent investigation into this event. There is no valid reason for the purposes of locus standi to distinguish the applicant's situation from that of a spouse."

${ }^{38}$ EUROPEAN COURT OF HUMAN RIGHTS. Second Section. Koku. vs. Turkey (Application n. ${ }^{\circ}$ 27305/95), j. 31.5.2005. Disponível em: <http://www.echr.coe.int/echr/>. Acesso em: 30 set. 2008. Ver, em especial, o $\$ 168$ : “Concerning the applicant's final complaint, the Court has previously found that distress and anguish caused to applicants as a result of the disappearance of their close relatives and their inability to find out what had happened to those relatives, coupled with the manner in which their complaints were dealt with by the authorities, constituted inhuman and degrading treatment contrary to Article 3 of the Convention (see, inter alia, Timurtaş, cited above, $₫ 98$, and İpek v. Turkey, no. 25760/94, $₫ 183$, ECHR 2004 (extracts)). In reaching its conclusions, the prolonged and continuing periods of uncertainty and apprehension suffered by the applicants were determinant factors for the Court (see Timurtaş, cited above, $\$ 98$; Ipek, cited above, $\S 183$; Orhan v. Turkey, no. 25656/94, §360, 18 June 2002)." 
reconhecimento simbólico da violação de determinado direito fundamental. É o caso, por exemplo, da viúva que deseja ver seu falecido esposo considerado inocente perante a sociedade. ${ }^{39}$

Todavia, há certos direitos personalíssimos e que não podem ser transmitidos pela morte, como, por exemplo, continuar uma ação em que o de cujus buscava o reconhecimento ao direito à eutanásia. ${ }^{40}$

Em outros casos, como a representação de menores, estes podem dirigir-se à Corte, por exemplo, para a defesa de seus direitos perante seus familiares ou, ainda, por meio de uma mãe em conflito com as autoridades de

${ }^{39}$ No caso Nölkenbockhoff vs. Alemanha, o Bundesverfassungsgericht negou à viúva a possibilidade de comprovar a inocência de seu falecido esposo, razão pela qual ela ingressou perante a Corte Européia, pleiteando a qualidade de vítima (Cf. EUROPEAN COURT OF HUMAN RIGHTS. Plenary. Nölkenbockhoff vs. Germany (Application n. ${ }^{\circ}$ 10300/83), j. 25.8.1987. Disponível em: <http://www.echr.coe.int/echr/>. Acesso em: 30 set. 2008. Ver, em especial, o $\$ 33$ : “The principle of the presumption of innocence is intended to protect "everyone charged with a criminal offence" from having a verdict of guilty passed on him without his guilt having been proved according to law. It does not follow, however, that a decision whereby the innocence of a man "charged with a criminal offence" is put in issue after his death cannot be challenged by his widow under Article 25 (art. 25). She may be able to show both a legitimate material interest in her capacity as the deceased's heir and a moral interest, on behalf of herself and of the family, in having her late husband exonerated from any finding of guilt (see, mutatis mutandis, the Deweer judgment of 27 February 1980, Series A no. 35, pp. $19-20, \S 37)$. As was pointed out by the Delegate, such is indeed the position in the present case. In the circumstances, Mrs. Nölkenbockhoff can consequently claim to be a "victim" within the meaning of Article 25 (art. 25). The Court would, moreover, point out that the German Constitutional Court, whose procedure of individual petitions is similar to the one established under the Convention (see the Klass and Others judgment of 6 September 1978, Series A no. 28, p. 19, $\$ 36$ ), did not dismiss Mrs. Nölkenbockhoff's application for lack of locus standi (see paragraph 22 above).").

${ }^{40}$ EUROPEAN COURT OF HUMAN RIGHTS. Fourth Section. Sanles Sanles vs. Spain (Application n. ${ }^{\circ}$ 48335/99). Decision of 26.10.2000 (Inadmissible). Disponível em: <http:// www.echr.coe.int/echr/>. Acesso em: 30 set. 2008. Ver, em especial, o seguinte trecho: "The Court concludes that the applicant cannot act on Mr. Sampedro's behalf and claim to be a victim of Articles 2, 3, 5, 8, 9 and 14 of the Convention, as required by Article 34. It follows that this part of the application is incompatible ratione personae with the provisions of the Convention for the purposes of Article $35 \$ 1$ and must be rejected in accordance with Article $35 \$ 4$." quem critica as decisões e o comportamento à luz dos direitos fundamentais garantidos pela Convenção. ${ }^{41}$

Desse modo, ponderou a Corte que as condições regentes das petições individuais não coincidem com os critérios nacionais referentes ao locus standi (legitimidade das partes), o que transmite a ideia de autonomia do direito de petição individual no plano internacional, independentemente do plano interno. Assim, os elementos fixados por esta jurisprudência podem ser aplicados a outros procedimentos de tratados de direitos humanos que requerem a condição de vítima para o exercício de petição individual, ${ }^{42}$ configurando o mecanismo de "fertilização cruzada" na proteção internacional dos direitos humanos. ${ }^{43}$

\subsection{Sistema interamericano}

A noção de "vítima” tem experimentado considerável expansão, no âmbito do direito internacional dos direitos humanos, principalmente por meio da construção jurisprudencial dos Órgãos de proteção internacionais, os quais passaram a especificar, em vítimas diretas e indiretas, vítimas potenciais, isto é, as que demonstram

${ }^{41}$ EUROPEAN COURT OF HUMAN RIGHTS. Grand Chamber. Scozzari and Giunta vs. Italy (Application(s) $n .^{\circ}(s) 39221 / 98$ e 41963/98), j. 13.7.2000. Disponível em: <http://www.echr. coe.int/echr/>. Acesso em: 30 set. 2008. Ver, em especial, o $\$ 138$ : “The Court points out that in principle a person who is not entitled under domestic law to represent another may nevertheless, in certain circumstances, act before the Court in the name of the other person (see, mutatis mutandis, the Nielsen v. Denmark judgment of 28 November 1988, Series A no. 144 , pp. $21-22, \$ \$ 56-57)$. In particular, minors can apply to the Court even, or indeed especially, if they are represented by a mother who is in conflict with the authorities and criticises their decisions and conduct as not being consistent with the rights guaranteed by the Convention. Like the Commission, the Court considers that in the event of a conflict over a minor's interests between a natural parent and the person appointed by the authorities to act as the child's guardian, there is a danger that some of those interests will never be brought to the Court's attention and that the minor will be deprived of effective protection of his rights under the Convention. Consequently, as the Commission observed, even though the mother has been deprived of parental rights - indeed that is one of the causes of the dispute which she has referred to the Court - her standing as the natural mother suffices to afford her the necessary power to apply to the Court on the children's behalf, too, in order to protect their interests."

${ }^{42}$ TRINDADE, Antônio Augusto Cançado. Tratado de direito internacional dos direitos humanos. Porto Alegre: Sergio Antonio Fabris Editor, 2003, p. 489. v. 3.

${ }^{43}$ Sobre o fenômeno da "fertilização cruzada", ver por todos DELMAS-MARTY, Mireille. Três desafios para um direito mundial. Rio de Janeiro: Lúmen Júris. 2003. 
um interesse pessoal potencial reconhecidamente na solicitação de seus direitos. ${ }^{44}$

O sistema interamericano possui peculiaridades que o distingue dos demais sistemas regionais e globais de proteção dos direitos humanos. Nesse contexto, a Convenção Americana avança em relação aos demais, em especial na legitimidade das partes para a causa. Ela amplia o direito de petição inclusive para terceiros, em função do tratamento particular que a violação dos direitos contidos na Convenção apresenta - detidos incomunicáveis ou desaparecidos, dentre outras situações. ${ }^{45}$

Embora ainda não tenha o acesso universal do sujeito à Corte Interamericana, o sistema interamericano desenvolveu evoluções em torno da participação do indivíduo perante o processo de tomada de decisão em matéria de direitos humanos ao longo de sua caminhada institucional. No ano de 2001, uma reforma do Regulamento da Corte Interamericana permitiu a participação do indivíduo de forma plena, quando o processo já estivesse no âmbito de apreciação da Corte Interamericana. ${ }^{46}$

Durante o seu Octogésimo Segundo Período Ordinário de Sessões, na sessão celebrada no dia 29 de janeiro de 2009, a Corte Interamericana apresentou a Exposição de Motivos da Reforma Regulamentar. ${ }^{47}$ Nesse documento, a Corte Interamericana reconhece que se en- contra inserida em um processo de reforma regulamentar cuja primeira fase foi concluída com as modificações expostas nesse documento.

Nesse momento institucional, a Corte Interamericana abriu-se para o diálogo em foros acadêmicos e institucionais de discussão, bem como fortaleceu suas relações de intercâmbio e debates com os Estados-Membros da OEA, com a Comissão Interamericana e com a sociedade civil, aceitando sugestões e comentários críticos dos diversos atores e usuários do sistema interamericano sobre a reforma de seu Regulamento.

Dentre os temas objeto de modificação, ${ }^{48}$ o tratamento conferido à "vítima" e a participação de amicus curiae no processo de tomada de decisão são os assuntos que mais possuem identidade com o objeto desta pesquisa.

A partir dessa alteração, com vistas a fortalecer a participação da suposta vítima no processo, a Corte Interamericana considerou oportuno reformar o Regulamento, de modo que as declarações da suposta vítima não sejam consideradas provas testemunhais, isto é, não precisam ser juramentadas. Assim, as declarações das supostas vítimas serão valoradas, no contexto do caso, levando em conta as características especiais das declarações.

A Corte Interamericana considerou apropriado omitir do regulamento qualquer referência aos familiares das supostas vítimas, uma vez que, de acordo com os precedentes da Corte Interamericana, em determinadas circunstâncias, os familiares também serão considerados vítimas e, posteriormente, poderão ser credores de reparações que a Corte Interamericana possa estabelecer no futuro. Desse modo, esses familiares serão considerados como supostas vítimas e lhes serão aplicáveis todas as disposições regulamentares referentes a esta situação.

${ }^{48}$ Foram objeto de reflexão os seguintes temas: procedimento de supervisão de cumprimento de sentenças; procedimento de supervisão de medidas provisórias; celebração de sessões da Corte fora de sua sede; oportunidade processual para apresentar amicus curiae; apresentação de escritos por meios eletrônicos; prazos para a apresentação do escrito de petições, argumentos e provas e do escrito de contestação da demanda; prazo para a apresentação dos anexos aos escritos submetidos pelas partes; prova testemunhal e pericial, momento processual oportuno para substituir o perito ou a testemunha e momento processual oportuno para impugná-los; e qualidade da declaração da vítima de um caso. 


\section{A intervenção de terceiros (amicus curiae) e a contribuição para o acesso aos sistemas regionais de proteção}

\subsection{Sistema europeu}

A intervenção de terceiros perante o processo de tomada de decisão em matéria de direitos humanos está prevista no artigo 36 da Convenção ${ }^{49}$ sob duas modalidades: (1) a interferência de um Estado-Parte com a formulação de observações por escrito, bem como a participação em audiências nos processos perante uma das seções ou o Tribunal Pleno em que um nacional seu figurar como autor da petição e (2) qualquer pessoa ou Estado-Parte interessado na contribuição da administração da justiça, para o processo de tomada de decisão poderá - mediante convite do Presidente da Corte - participar das audiências e com observações escritas.

A primeira hipótese se aproxima de um assistente processual civil e se justifica em função da proteção diplomática exercida por um Estado para seu nacional, na defesa de direitos fundamentais violados por outro Estado. ${ }^{50}$ Por essa razão, uma das cópias da queixa é enviada ao Estado-Parte do qual o requerente é cidadão. ${ }^{51}$

O primeiro caso em que a situação contida no $\$ 1^{\circ}$ do artigo 36 restou aplicada foi em Soering vs. Reino Unido, em que os Estados Unidos encaminharam um pedido de extradição ao Reino Unido de um cidadão alemão, a fim de ser julgado por um crime passível de pena de morte. O Estado da nacionalidade do requerente - a República Federal da Alemanha - também pleiteou acesso

49 "Artigo $36^{\circ}$ - Intervenção de terceiros. 1. Em qualquer assunto pendente numa seção ou no tribunal pleno, a Alta Parte Contratante da qual o autor da petição seja nacional terá o direito de formular observações por escrito ou de participar nas audiências. 2. No interesse da boa administração da justiça, o presidente do Tribunal pode convidar qualquer Alta Parte Contratante que não seja parte no processo ou qualquer outra pessoa interessada que não o autor da petição a apresentar observações escritas ou a participar nas audiências."

${ }^{50}$ BARRETO, Irineu Cabral. A Convenção europeia dos direitos do homem anotada. 3. ed. Coimbra: Coimbra, 2005, p. 308.

${ }^{51}$ Esta determinação está contida no artigo $44, \S 1^{\circ}, a$, do Regulamento da Corte Européia: "Quando uma queixa introduzida nos termos do artigo 34 da Convenção é levada ao conhecimento da Parte contratante requerida nos termos do artigo 54, n. ${ }^{\circ}$ 2, b, do presente Regulamento, o Greffier envia ao mesmo tempo uma cópia da queixa à Parte contratante de que é cidadão o requerente no respectivo caso. Ele notifica também esta Parte contratante da decisão de ter uma audiência no caso." aos autos, em função de dois motivos principais: (a) considerações humanitárias e (b) a preocupação em proteger o seu nacional, tendo em vista que o seu próprio pedido de extradição tinha sido recusado. ${ }^{52}$

A segunda hipótese - a de que qualquer EstadoParte ou pessoa interessada seja convidado(a) a participar do processo de tomada de decisão, desde que não esteja em nenhum dos polos do processo - recebe críticas dos teóricos, ${ }^{53}$ pois não consagra um verdadeiro processo de intervenção de terceiros. Há a dependência do convite (ou autorização) do presidente de uma das seções para a apresentação de informações escritas ou participação nas audiências, as quais estão sendo utilizadas com prudência e moderação pela Corte..$^{54}$

São raros os pedidos de intervenção de um terceiro Estado-Parte. ${ }^{55}$ Por outro lado, inúmeras organizações não governamentais elaboram frequentes pedidos de

${ }^{52}$ BARRETO, Irineu Cabral. A convenção europeia dos direitos do homem anotada. 3. ed. Coimbra: Coimbra, 2005, p. 309.

${ }^{53}$ Por todos, ver BARRETO, Irineu Cabral. A convenção europeia dos direitos do homem anotada. 3. ed. Coimbra: Coimbra Editora, 2005. p. 309.

${ }^{54}$ BARRETO, Irineu Cabral. A convenção europeia dos direitos do homem anotada. 3. ed. Coimbra: Coimbra, 2005. p. 309. $\mathrm{O}$ artigo $44, \$ 2^{\circ}$, $a$ e $b$, do Regulamento da Corte Européia prevê determinados procedimentos para a intervenção de terceiros: "(a) Uma vez a queixa levada ao conhecimento da Parte contratante requerida nos termos do artigo $51, \S 1^{\circ}$, ou do artigo $54, \$ 2^{\circ}$, alínea $b$, do presente Regulamento, o Presidente da Seção pode, no interesse de uma boa administração da justiça, como prevê o artigo $36, \$ 2^{\circ}$, da Convenção, convidar ou autorizar outra Parte contratante, que não é parte na instância ou qualquer pessoa interessada que não seja requerente, a apresentar observações escritas ou, em circunstâncias excepcionais, a tomar parte nas audiências. (b) Os pedidos de autorização para este fim devem ser devidamente fundamentados e apresentados por escrito numa das línguas oficiais, como exige o artigo $34, \S 4^{\circ}$, do presente Regulamento, ao mais tardar doze semanas após a queixa ter sido levada ao conhecimento da Parte contratante requerida. O Presidente da Seção pode, a título excepcional, fixar outro prazo."

${ }^{55}$ No julgamento Ruiz-Mateos, de 23.6.1993, Portugal e Alemanha foram admitidos a intervir no caso relativo à Espanha. (Cf. EUROPEAN COURT OF HUMAN RIGHTS. Plenary. Ruiz-Mateos vs. Spain (Application n. ${ }^{\circ}$ 12952/87), j. 23.6.1993. Disponível em: <http://www.echr.coe.int/echr/>. Acesso em: 29 jun. 2008. Ver, em especial, o $₫ 5^{\circ}$ : "On 10 April and 30 June 1992 respectively the President had authorised, under Rule 37 para. 2, the Government of the Federal Republic of Germany and the Government of the Portuguese Republic to submit written observations on the applicability of Article 6 para. 1 (art. 6-1) of the Convention to constitutional courts. These observations reached the registry on 10 June and 27 August."). 
intervenção, ${ }^{56}$ mas o presidente da Corte apenas deferiu algumas destas pretensões..$^{57} 58$

Ademais, o Protocolo n. ${ }^{\circ} 14$ institui um novo item ao artigo 36 da Convenção. ${ }^{59}$ Esta nova normativa permite a intervenção no processo do Comissário dos Direitos do Homem. Ele já podia intervir por iniciativa do Presidente da Corte, mas agora ganha autonomia para escolher em qual processo da seção ou do Tribunal Pleno intervirá, ${ }^{60} \mathrm{o}$ que simboliza uma mudança institucional importante na conformação da atuação dos atores no processo de tomada de decisão em direitos humanos.

\subsection{Sistema Interamericano}

Quanto à participação dos amicus curiae, a instituição do artigo $41^{61}$ no Regulamento da Corte Interamericana confirmou o novo colorido que o processo de tomada de decisão em matéria de direitos humanos possui com o fluxo comunicativo dos participantes oriundos da sociedade civil.

$\mathrm{O}$ escrito de quem deseja atuar como amicus curiae poderá ser apresentado ao Tribunal, junto com seus anexos, em qualquer momento do processo contencioso, desde que dentro dos 15 dias posteriores à celebração da audiência pública. Nos casos em que não for

${ }_{56}$ Os pedidos podem ser conferidos nos seguintes julgados: Godi (9.4.1984); Manole (2.8.1984); Ashingdane (28.5.1985); Lingens (28.8.1986); Glasenapp e Kosiek (28.8.1986); Monell e Morris (2.3.1987); Leander (26.3.1987); Capuano (25.6.1987); Brogan (29.11.1988); Soering (2.7.1989); Caleffi (24.5.1991); e Vocaturo (24.5.1991).

${ }^{57}$ Os seguintes casos: Manole (2.8.1984); Ashingdane (28.5.1985); Lingens (28.8.1986); Monell e Morris (2.3.1987); (26.3.1987); Capuano (25.6.1987); Brogan (29.11.1988); e Soering (2.7.1989).

${ }^{58}$ BARRETO, Irineu Cabral. A convenção europeia dos direitos do homem anotada. 3. ed. Coimbra: Coimbra, 2005. p. 310.

59 Trata-se do $₫ 3^{\circ}$ : "Em qualquer assunto pendente numa seção ou tribunal pleno, o Comissário para os Direitos do Homem do Conselho da Europa poderá formular observações por escrito e participar de audiências."

${ }^{60}$ BARRETO, Irineu Cabral. A convenção europeia dos direitos do homem anotada. 3. ed. Coimbra: Coimbra, 2005. p. 310.

${ }^{61} \mathrm{O}$ escrito de quem deseje atuar como amicus curiae poderá ser apresentado ao Tribunal, junto com seus anexos, em qualquer momento do processo contencioso, desde que dentro dos 15 dias posteriores à celebração da audiência pública. Nos casos em que não for celebrada audiência pública, deverão ser remetidos dentro dos 15 dias posteriores à Resolução correspondente na qual se outorga prazo para o envio de alegações finais e prova documental. $\mathrm{O}$ escrito de amicus curiae, junto com seus anexos, será levado de imediato ao conhecimento das partes para sua informação, com prévia consulta à Presidência. celebrada audiência pública, deverá remetido, dentro dos 15 dias posteriores, à Resolução correspondente na qual se outorga prazo para o envio de alegações finais e prova documental. O escrito de amicus curiae, junto com seus anexos, será levado de imediato ao conhecimento das partes para sua informação, com prévia consulta à Presidência.

Logo, a participação do indivíduo, seja como suposta vítima, seja como interessado no processo, torna-se relevante para a construção da esfera pública em matéria dos valores fundamentais, em especial na formulação jurisprudencial do direito internacional dos direitos humanos.

\section{Análise crítica da medida comparativa dos sistemas regionais: o papel da fragmentação do direito na formação da esfera pública em matéria de direitos humanos}

A proposta desta pesquisa é colocar a prática dos sistemas regionais de proteção dos direitos humanos diante da formulação teórica tradicional acerca do papel do indivíduo no cenário internacional.

O Preâmbulo do Estatuto do Conselho da Euro$\mathrm{pa}^{62}$ reforça a ideia de liberdade e democracia no âmbito das comunidades europeias. O vínculo dos Estados aos valores morais e espirituais constitui o patrimônio comum de seus povos e permite a origem e o exercício das liberdades políticas e individuais, bem como a estruturação sobre proeminência do direito, em que, nestes fatores, se fundamenta todo o conteúdo democrático. Por essa razão, os membros da comunidade europeia, ao adotarem este patrimônio comum, para permitirem o exercício das liberdades fundamentais, estruturam os alicerces de seu sistema sobre uma concepção comum e um comum respeito aos direitos humanos, considerados interesses essenciais da comunidade. ${ }^{63}$

Um dos propósitos da coexistência de distintos instrumentos jurídicos está na ampliação e no fortalecimento da proteção dos direitos humanos. ${ }^{64}$

\footnotetext{
${ }^{62}$ O Estatuto foi adotado em Londres, no dia 5.5.1949.

${ }^{63}$ LIMA, José Antonio Farah Lopes de. Convenção européia de direitos humanos. Leme, São Paulo: J. H. Mizuno, 2007. p. 25.

${ }^{64}$ PIOVESAN, Flávia. Direitos humanos e o direito constitucional internacional. 7. ed. São Paulo: Saraiva, 2006. p. 242.
} 
Passa-se a ter, então, um reconhecimento de uma identidade do sujeito no âmbito dos sistemas regionais de proteção dos direitos humanos: em função da fragmentação, além do papel de vítima, o sujeito passa a ter o papel de fomentador do sistema com o acesso universal, contribuindo para o processo de tomada de decisão em matéria da luta contra a violação dos direitos humanos.

No contexto da Convenção Americana de Direitos Humanos, é possível compreender o bem comum como um conceito referente às condições de vida social que permite aos integrantes da sociedade alcançarem o maior grau de desenvolvimento pessoal e a maior vigência dos valores democráticos. Nesse sentido, a organização da vida social, na forma que se fortalece o funcionamento das instituições democráticas e que se preserve e se promova a plena realização dos direitos da pessoa humana, pode ser considerada um imperativo do bem comum. ${ }^{65}$

Desse modo, de nenhuma maneira se poderiam invocar a "ordem pública" e o "bem comum" como meios para suprimir um direito garantido pela Convenção Americana, ou para descaracterizá-lo de seu conteúdo real. A Corte Interamericana admite a dificuldade de precisar de modo inequívoco os conceitos de "ordem pública" e "bem comum", e que ambos os conceitos podem ser usados tanto para afirmar os direitos fundamentais de uma pessoa frente ao poder público, como para justificar limitações a esses direitos em nome dos interesses coletivos. Por essa razão, a Corte Interamericana delineia que tais conceitos, quando invocados como fundamento de limitações aos direitos humanos, devem ser objetos de uma interpretação estritamente comprometida às "justas exigências" de "uma sociedade democrática", que tenha em conta o equilíbrio entre os distintos interesses em jogo e a necessidade de se preservar o objeto e o fim da Convenção Americana ${ }^{66}$.

A esfera pública é definida por Jürgen Habermas como "uma rede adequada para a comunicação de con-

${ }^{65}$ CORTE INTERAMERICANA DE DERECHOS HUMANOS. Opinión consultiva OC-5/85, 13.11.1985. La colegiación obligatoria de periodistas (arts. 13 y 29 Convención Americana sobre Derechos Humanos). Disponível em: <http://www.corteidh.or.cr/>. Acesso em 23 ago. 2008. Ver, em especial, o $\$ 66$.

${ }^{66}$ CORTE INTERAMERICANA DE DERECHOS HUMANOS. Opinión consultiva OC-5/85, 13.11.1985. La colegiación obligatoria de periodistas (arts. 13 y 29 Convención Americana sobre Derechos Humanos). Disponível em: <http://www.corteidh.or.cr/>. Acesso em 23 ago. 2008. Ver, em especial, o $\$ 67$. teúdos, tomadas de posição e opiniões”, em que os fluxos comunicativos "são filtrados e sintetizados, a ponto de se condensarem em opiniões públicas enfeixadas em temas específicos." 67

A esfera pública não se equipara à sociedade; é apenas um elemento dela, que se reproduz a partir do agir comunicativo, no contexto de uma linguagem comum, em sintonia com a compreensão da prática comunicativa cotidiana. A esfera pública se conecta a funções gerais de reprodução do mundo da vida, ou a diferentes aspectos de validade do saber comunicativo por meio da linguagem comum. Entretanto, a esfera pública não se especializa em uma direção específica, pois constitui uma estrutura comunicativa "do agir orientado pelo entendimento, a qual tem a ver com o espaço social gerado no agir comunicativo, não com as funções nem com os conteúdos da comunicação cotidiana." 68

Os que atuam comunicativamente alimentam a esfera pública por meio de suas interpretações "negociadas cooperativamente", pois qualquer ambiente que se nutre da liberdade comunicativa que uns concedem aos outros se movimenta num espaço público, constituído por meio da linguagem. ${ }^{69}$

Nesse contexto, a criação de uma esfera pública em matéria de direitos humanos se faz necessária, na medida em que os sujeitos, diante de seu papel na formulação do peticionamento individual, podem almejar construir uma linguagem comum, para a proteção dos valores fundamentais expostos nos sistemas de proteção dos direitos humanos. Essa esfera pública deve incluir todos aqueles que buscam proteger e resguardar o conteúdo desrespeitado pelo agente violador, independentemente do tipo de sujeito que se apresenta perante o processo de tomada de decisão.

Com isso, novas perspectivas de compreensão e práticas nos processos em matéria de direitos humanos se apresentam, em que os instrumentos mais finos com os que se articulam e formulam os interesses das minorias já estão preparados, devendo, tão somente, ser "afinados"

${ }^{67}$ HABERMAS, Jürgen. Direito e democracia: entre facticidade e validade. 2. ed. Rio de Janeiro: Tempo Brasileiro, 2003.v. 2, p. 92.

${ }^{68}$ HABERMAS, Jürgen. Direito e democracia: entre facticidade e validade. 2. ed. Rio de Janeiro: Tempo Brasileiro, 2003.v. 2, p. 92.

${ }^{69}$ HABERMAS, Jürgen. Direito e democracia: entre facticidade e validade. 2. ed. Rio de Janeiro: Tempo Brasileiro, 2003.v. 2, p. 92. 
para alcançar uma interpretação dos valores fundamentais plurais e efetivos, isto é, conseguir um "processo público" por meio dessa interpretação. ${ }^{70}$

Compreender essa interpretação como um processo público não só tem seus limites, como também encerra certos perigos, tendo em vista que se apresenta como uma potente "dinamização" do "direito posto". A consequência é o que "se transcreve" e acaba sendo quantitativamente menor, não tendo o idêntico valor daquilo que "se crê", em especial a hermenêutica dos valores fundamentais nos âmbitos submetidos a tensões que existem nos próprios princípios constitucionais e nos valores constitucionais integrados ao sistema jurídico. ${ }^{71}$

A atualização dos valores constitucionais, por meio da liberdade experienciada e vivida pelos cidadãos, e da força normativa do âmbito público exigem muito de todos. O jurista, como intérprete constitucional - em sentido amplo e estrito - pode fazer muito em prol de sua projeção no âmbito social e garantir, assim, a liberdade da cidadania. Além disso, o cidadão tem que tomar "parte ativa" na positivação das liberdades existentes nas esferas estatais e da sociedade, contribuindo para assegurá-las e garanti-las, pois tudo isso constitui um dos objetivos primordiais de seu papel como intérprete, na ativação da cidadania democrática, mediante a configuração do status activus processualis entre a cidadania e os poderes públicos. ${ }^{72}$

$\mathrm{Na}$ formulação do seu conceito de Regime, Teubner assevera que um regime necessariamente não leva em consideração apenas o seu aspecto jurídico, e sim tem como metodologia os aportes políticos, imprescindíveis para a comunicação entre os diversos regimes, de acordo com a teoria dos sistemas.

Para Teubner, enquanto o direito é formado pela premissa das regras e princípios, um regime jurídico tem como elemento-chave a decisão, composta não apenas da interpretação das regras e dos princípios, mas da composição de ideias, valores, comportamentos (a pré-compreensão de Gadamer) na interpretação das normas.

\footnotetext{
${ }^{70}$ HÄBERLE, Peter. Pluralismo y constitución: estudios de teoría constitucional de la sociedad abierta. Madrid: Tecnos, 2002. p. 95.

${ }^{71}$ HÄBERLE, Peter. Pluralismo y constitución: estudios de teoría constitucional de la sociedad abierta. Madrid: Tecnos, 2002. p. 99.

${ }^{72}$ HÄBERLE, Peter. Pluralismo y constitución: estudios de teoría constitucional de la sociedad abierta. Madrid: Tecnos, 2002. p. 102.
}

Diante desse quadro, a fragmentação do direito no primeiro momento - é tida como elemento desagregador da unidade jurídica. De outro lado, considera-se, na verdade, uma oportunidade para o desenvolvimento de temas a partir de contribuições oriundas das diferentes esferas normativas autônomas que se encontram no plano do direito internacional.

É a fragmentação do direito que permite, na realidade, que ocorra a fertilização cruzada entre as cortes de proteção dos direitos humanos e o aumento de densidade teórica sobre o tema, a ponto de o sistema interamericano estar mais avançado em diversas medidas de cunho procedimental sobre o papel do sujeito, como a ampliação do conceito de vítima e o avanço no procedimento do amicus curiae.

Portanto, ainda que não haja a previsão normativa na Convenção Americana ou o reconhecimento da comunidade internacional dos Estados Soberanos sobre o papel do indivíduo no cenário internacional, o que se percebe são um extremo avanço e um aproveitamento das janelas de oportunidades para a contribuição dos indivíduos na construção do acervo normativo internacional, seja de forma direta, seja ainda pela via indireta da interpretação, tornando os fragmentos que possibilitam a participação do indivíduo uma premissa de universalização desse valor.

\section{Considerações finais}

A formação da sociedade no plano internacional exige cada vez mais uma "procedimentalização" nas relações sociais que o indivíduo estabelece no mundo globalizado. As relações com os direitos humanos denotam este aspecto, na medida em que, em função da velocidade da informação e da organização dos grupos de interesse sobre o tema, tem-se acesso às violações e privações que os indivíduos sofrem no contexto de seu patrimônio jusfundamental. A percepção de como evitar esta violação e de como combatê-la se faz presente no estudo dos sistemas de proteção, o qual é desenvolvido e, ainda que tenha poucos recursos, busca garantir a efetividade na proteção da dignidade humana.

Cada sistema regional funciona em seu próprio ritmo e vive seu próprio momento. $\mathrm{O}$ sistema interamericano busca aperfeiçoar cada vez mais a coordenação dos 
trabalhos entre a Comissão e a Corte, enquanto o sistema europeu busca definir o seu status com a funcionalidade e racionalidade de uma Corte Constitucional para a Europa. Todavia, ambos os sistemas caminham no sentido da construção de uma "esfera pública" em matéria de direitos humanos, a qual se observa pela adoção de métodos de julgamento, da "fertilização cruzada" dos julgamentos e do desenvolvimento de valores comuns, concernentes à proteção da dignidade humana.

Não obstante a controvérsia teórica apresentada acerca do direito de petição individual, a postura defendida pelo estudo comparativo, seja mediante a comparação de direitos fundamentais, seja pelo método da Internacionalização dos Direitos, espanca qualquer dúvida sobre a realidade que se apresenta.

Em um momento que cada vez mais a esfera internacional se agiganta sobre os sistemas jurídicos nacionais, a participação consciente dos indivíduos no processo de tomada de decisão se faz necessária também no âmbito internacional. A formulação teórica da sociedade aberta universal, nesse sentido, tem seu alento na construção jurisprudencial realizada pelos sistemas regionais de proteção dos direitos humanos.

O sistema europeu e o sistema interamericano, que se encontram em diferentes momentos e possuem diferentes velocidades, desenvolveram um pano de fundo comum, acerca da necessidade de se respeitar a dignidade da pessoa humana. Todavia, no momento atual, em que se examina o processo de fertilização cruzada à luz da Internacionalização dos Direitos, percebe-se um sistema interamericano preocupado em evoluir em sua saga na busca da concretização dos direitos humanos e em um modelo de racionalidade que permita o acesso direto do indivíduo perante a Corte, sem a destruição do patrimônio simbólico construído pela Comissão Interamericana; enquanto o sistema europeu, a seu turno, se vê em um momento de atenção, principalmente no choque entre as demandas da economia (o "combate" aos imigrantes ilegais) e a alma construída em torno dos direitos humanos (a proteção da pessoa humana, independentemente de sua origem ou de seu patrimônio jurídico).

O papel do sujeito perante os sistemas de proteção dos direitos humanos se revela sobre duas dimensões. A primeira, a dimensão de vítima, se apresenta como o elo inicial para a construção/revelação do que Mireille
Delmas-Marty almeja como valor comum. A segunda dimensão, por outro lado, está na função de fomentador do sistema de proteção, participando ativamente na construção jurisprudencial que define os conceitos a serem utilizados pelo Direito Internacional dos Direitos Humanos, papel de intérprete.

Essa aproximação entre os sistemas, por meio das ações do sujeito, permite o desenvolvimento de uma esfera pública sobre os direitos humanos, na qual os fluxos comunicativos, especialmente os referentes ao fomento do papel do sujeito, vislumbram a formação de uma sociedade aberta de caráter universal, cuja consequência se apresenta na irradiação do conteúdo previsto nos direitos fundamentais e nos direitos humanos a todos que compartilham com a premissa de sua criação.

Portanto, percebe-se que a fragmentação do direito permite o elo de conexão entre os sistemas regionais diversos, demonstrando que se cuida, na verdade, de uma nova empreitada evolutiva do direito internacional, como demonstrado no parecer ONU de 1949. Mesmo que não haja o reconhecimento da comunidade internacional dos Estados Soberanos sobre o papel do indivíduo no cenário internacional, o que se percebe é um extremo avanço e um aproveitamento das janelas de oportunidades para a contribuição dos indivíduos na construção do acervo normativo internacional, seja de forma direta, seja ainda pela via indireta da interpretação, tornando os fragmentos que possibilitam a participação do indivíduo uma premissa de universalização desse valor.

\section{Referências}

ALVES, Jorge de Jesus Ferreira. A convenção europeia dos direitos do homem anotada e protocolos adicionais anotados. Porto: Legis, 2008.

BARRETO, Irineu Cabral. A convenção europeia dos direitos do homem anotada. 3. ed. Coimbra: Coimbra Editora, 2005.

CORTE INTERAMERICANA DE DERECHOS HUMANOS. Opinión consultiva OC-2/82, 24.9.1982. $\mathrm{El}$ efecto de las reservas sobre la entrada en vigencia de la Convención Americana sobre Derechos Humanos. Disponível em: $<$ http://www.corteidh.or.cr/>. Acesso em: 28 jun. 2008. 
CORTE INTERAMERICANA DE DERECHOS HUMANOS. Opinión consultiva OC-5/85, 13.11.1985. La colegiación obligatoria de periodistas (arts. 13 y 29 Convención Americana sobre Derechos Humanos). Disponível em: <http://www.corteidh.or.cr/>. Acesso em 23 ago. 2008.

CORTE INTERAMERICANA DE DERECHOS HUMANOS. Caso Castillo Petruzzi y otros vs. Perú. Sentencia de 4.9.1998 (Excepciones Preliminares). Voto do Juiz Cançado Trindade. Disponível em: <http://www. corteidh.or.cr/>. Acesso em: 28 jun. 2008.

DELMAS-MARTY, Mireille. Três desafios para um direito mundial. Rio de Janeiro: Lúmen Júris, 2003.

DUPUY, Pierre-Marie. L'Unité de L'Ordre Juridique International. Cours général de droit International public (2000): académie de droit international de la haye. Leiden: Martinus Nijhoff Publishers, 2003.

EUROPEAN COMMISSION OF HUMAN RIGHTS. Decision of 13.7.1983 on the admissibility of the Application n. ${ }^{\circ}$ 9502/81. S. vs. The United Kingdom. Disponível em: $<$ http://www.echr.coe.int/echr/>. Acesso em: 30 jun. 2008.

EUROPEAN COURT OF HUMAN RIGHTS. Chamber. Vocaturo. vs. Italy (Application n. $\left.{ }^{\circ} 11891 / 85\right)$, j. 24.5.1991. Disponível em: <http://www.echr.coe.int/echr/>. Acesso em: 30 jun. 2008.

EUROPEAN COURT OF HUMAN RIGHTS. Chamber. X. vs. France (Application n. ${ }^{\circ}$ 18020/91), j. 31.3.1992. Disponível em: <http://www.echr.coe.int/echr/>. Acesso em: 30 jun. 2008.

EUROPEAN COURT OF HUMAN RIGHTS. Fourth Section. Sanles Sanles vs. Spain (Application n. ${ }^{\circ} 48335 / 99$ ). Decision of 26.10.2000 (Inadmissible). Disponível em: <http://www.echr.coe.int/echr/>. Acesso em: 30 set. 2008.

EUROPEAN COURT OF HUMAN RIGHTS. Fourth Section. Ünal Tekeli vs. Turkey (Application n. ${ }^{\circ}$ 29865/96), j. 16.11.2004. Disponível em: <http://www.echr.coe.int/ echr/>. Acesso em: 26 jun. 2008.

EUROPEAN COURT OF HUMAN RIGHTS. Fourth Section. Velikova vs. Bulgaria (Application n. ${ }^{\circ} 41488 / 98$ ). Decision of 18.5.1999. Disponível em: <http://www.echr. coe.int/echr/>. Acesso em: 30 jun. 2008.

EUROPEAN COURT OF HUMAN RIGHTS. Grand Chamber. Apicella vs. Italy (Application n. ${ }^{\circ}$ 64890/01), j. 29.3.2006. Disponível em: <http://www.echr.coe.int/ echr/>. Acesso em: 26 jun. 2008.
EUROPEAN COURT OF HUMAN RIGHTS. Grand Chamber. Scozzari and Giunta vs. Italy (Application(s) $n .{ }^{\circ}(s)$ 39221/98 e 41963/98), j. 13.7.2000. Disponível em: $<$ http://www.echr.coe.int/echr/>. Acesso em: 30 set. 2008.

EUROPEAN COURT OF HUMAN RIGHTS. Plenary. Golder vs. The United Kingdom (Application n. ${ }^{\circ} 4451 / 70$ ), j. 21.2.1975. Disponível em: <http://www.echr.coe.int/ echr/>. Acesso em: 21 ago. 2008.

EUROPEAN COURT OF HUMAN RIGHTS. Plenary. Ireland vs. The United Kingdom (Application n. ${ }^{\circ}$ 5310/71), j. 18.1.1978. Disponível em: <http://www.echr.coe.int>. Acesso em: 25 jun. 2008.

EUROPEAN COURT OF HUMAN RIGHTS. Plenary. Nölkenbockhoff vs. Germany (Application n. ${ }^{\circ}$ 10300/83), j. 25.8.1987. Disponível em: <http://www.echr.coe.int/ echr/>. Acesso em: 30 set. 2008.

EUROPEAN COURT OF HUMAN RIGHTS. Plenary. Norris vs. Ireland (Application n. ${ }^{\circ}$ 10581/83), j. 26.10.1988. Disponível em: <http://www.echr.coe.int/echr/>. Acesso em: 25 jun. 2008.

EUROPEAN COURT OF HUMAN RIGHTS. Plenary. Ruiz-Mateos vs. Spain (Application n. ${ }^{\circ}$ 12952/87), j. 23.6.1993. Disponível em: <http://www.echr.coe.int/ echr/>. Acesso em: 29 jun. 2008.

EUROPEAN COURT OF HUMAN RIGHTS. Second Section. Koku. vs. Turkey (Application n. ${ }^{\circ}$ 27305/95), j. 31.5.2005. Disponível em: <http://www.echr.coe.int/ echr/>. Acesso em: 30 set. 2008.

EUROPEAN COURT OF HUMAN RIGHTS. Second Section. Shamayev and Others vs. Georgia and Russia (Application n..$^{\circ}$ 36378/02). Disponível em: <http://www. echr.coe.int/echr/>. Acesso em: 25 jun. 2008.

EUROPEAN COURT OF HUMAN RIGHTS. Third Section. Jorge Nina Jorge and Others vs. Portugal (Application n. ${ }^{\circ}$ 52662/99), j. 19.2.2004. Disponível em: $<$ http://www.echr.coe.int/echr/>. Acesso em: 27 ago. 2008.

EUROPEAN COURT OF HUMAN RIGHTS. Third Section. Örs. vs. Turkey (Application n. ${ }^{\circ}$ 46213/99), j. 13.11.2003. Disponível em: <http://www.echr.coe.int/ echr/>. Acesso em: 30 jun. 2008.

EUROPEAN COURT OF HUMAN RIGHTS. Third Section. Segi and Gestoras Pro-Amnistia vs. 15 States of European Union (Application(s) n. ${ }^{\circ}(s) 6422 / 02$ e 9916/02), Decision of inadmissible in 23.5.2002. Disponível em: $<$ http://www.echr.coe.int/echr/>. Acesso em: 25 jun. 2008. 
HÄBERLE, Peter. Pluralismo y constitución: estudios de teoría constitucional de la sociedad abierta. Madrid: Tecnos, 2002.

HABERMAS, Jürgen. Direito e democracia: entre facticidade e validade. 2. ed. Rio de Janeiro: Tempo Brasileiro, 2003. v. 2.

JIMÉNEZ DE ARÉCHAGA, Eduardo. El derecho internacional contemporâneo. Madrid: Tecnos, 1980.

LIMA, José Antonio Farah Lopes de. Convenção européia de direitos humanos. Leme, São Paulo: J. H. Mizuno, 2007, p. 33 .

PACHECO GÓMEZ, Máximo. La Competencia Consultiva de la Corte Interamericana de Derechos Humanos. In: CORTE INTERAMERICANA DE DERECHOS HUMANOS. El sistema interamericano de protección de los derechos humanos en el umbral de siglo xxi. Memoria del Seminario. 2. ed., tomo I, 23 y 24 de Noviembre de 1999. Relator: Antônio Augusto Cançado Trindade. San José, Costa Rica: CORTE Interamericana, 2003.

PIOVESAN, Flávia. Direitos humanos e o direito constitucional internacional. 7. ed. São Paulo: Saraiva, 2006.
REUTER, Paul. Droit international public. 7. ed. Paris, França: PUF, 1993.

REZEK, José Francisco. Direito internacional público. 9. ed. rev. São Paulo: Saraiva, 2002.

RUIZ DE SANTIAGO, Jaime. Diagnóstico de la realidad de los derechos humanos en América Latina: tendencias y desafios. In: TRINDADE, Antônio Augusto Cançado; RUIZ DE SANTIAGO, Jaime (Org.). La nueva dimensión de las necessidades de protección del ser humano en el inicio del siglo xxi. San José: Impresora Gossestra Internacional, 2004.

TRINDADE, Antônio Augusto Cançado. El nuevo reglamento de la Corte Interamericana de Derechos Humanos (2000): la emancipación del ser humano como sujeito del derecho internacional de los derechos humanos. Revista Universitas: relações internacionais, v. 1, n. 2, p. 09-39, jan./jul. 2003.

TRINDADE, Antônio Augusto Cançado. Tratado de direito internacional dos direitos humanos. Porto Alegre: S. A. Fabris Editor, 2003. v. 3

VARELLA, Marcelo Dias. Direito internacional público. São Paulo: Saraiva, 2009. 
Para publicar na Revista de Direito Internacional, acesse o endereço eletrônico www.rdi.uniceub.br ou www.brazilianjournal.org.

Observe as normas de publicação, para facilitar e agilizar o trabalho de edição. 